\title{
revisão de literatura Neurobiologia da Cannabis: do sistema endocanabinoide aos transtornos por uso de Cannabis
}

\author{
Neurobiology of Cannabis: from the endocannabinoid \\ system to cannabis-related disorders
}

José Luis G. Pinho Costa², Lucas 0. Maia², Orlandi-Mattos P.2, João C. Villares², Manuel A. Fernandez

Esteves'

\section{RESUMO}

Objetivos: Diante das lacunas na efetividade das terapêuticas para transtornos por uso de Cannabis, a droga ilícita mais consumida no mundo, este trabalho propõe-se a rever os conhecimentos sobre o substrato neuroanatômico, biomolecular e celular do sistema endocanabinoide, descrever os mecanismos de neuroplasticidade dependente dos canabinoides e relacioná-los com a neurobiologia dos transtornos por uso de Cannabis (abuso e dependência). Métodos: Recorreu-se às bases de dados Medline, Scopus e ISI Web of Knowledge; as palavras-chave pesquisadas foram "Cannabis", "neurobiology", "endocannabinoid system", "endocannabinoids", "receptors, cannabinoid", "neuronal plasticity", "long-term synaptic depression", "long-term potentiation", "marijuana abuse" e "tetrahydrocannabinol". Foram incluídos 80 trabalhos nesta revisão. Discussão: A distribuição neuroanatômica, celular e biomolecular do sistema endocanabinoide adequa-se perfeitamente às suas funções de neuromodulação (via neuroplasticidade e metaplasticidade), nomeadamente em vias relacionadas aos transtornos por uso de substâncias. Os canabinoides exógenos perturbam essas funções. Conclusão: O sistema endocanabinoide contribui para a definição de setpoints em diversas vias neuronais, incluindo vias cruciais na instalação de transtornos por uso de substâncias; com o uso de Cannabis, esses setpoints tornar-se-ão mais permissivos, facilitando os transtornos por uso de Cannabis. Os avanços no entendimento da neurobiologia da Cannabis abrem uma janela de oportunidades para novas estratégias terapêuticas nos transtornos por uso de Cannabis.

\section{ABSTRACT}

Objectives: Given the challenges arising from the poor effectiveness of therapies for Cannabis-related disorders, the most commonly used illicit drug in the world, this paper aims to review the present knowledge about the neuroanatomic, biomolecular and cellular substrate of the endocannabinoid system, describing the mechanisms of cannabinoid-dependent neuronal plasticity and relating them with the neurobiology of Cannabis-related disorders (abuse and dependence). Methods: Medline, Scopus and ISI Web of Knowledge were searched for the keywords "Cannabis",

1 Universidade do Porto, Faculdade de Medicina (FMUP), Porto, Portugal.

2 Universidade Federal de São Paulo (Unifesp), Departamento de Psicobiologia, Centro Brasileiro de Informações sobre Drogas Psicotrópicas (CEBRID).

Entregue em $5 / 5 / 2011$ Aprovado em 9/5/2011
Endereço para correspondência: Jose Luis G. Pinho Costa

Centro Brasileiro de Informações sobre Drogas Psicotrópicas (Cebrid), Departamento de Psicobiologia, Universidade Federal de São Paulo Rua Botucatu, 862, 10 andar - Edifício de Ciências Biomédicas - 04023-062 - São Paulo, SP, Brasil Telefone: (11) 2149-0155/Telefax: (11) 5084-2793

E-mail:med05009@med.up.pt 


\section{Keywords}

Neurobiology, endocannabinoid system, neuronal plasticity, Cannabis-related disorders. "neurobiology", "endocannabinoid system", "endocannabinoids", "receptors, cannabinoid", "neuronal plasticity", "long-term synaptic depression", "long-term potentiation", "marijuana abuse" and "tetrahydrocannabinol". Eighty studies were included in this review. Discussion: The neuroanatomical, cellular and biomolecular characterization of the endocannabinoid system serves perfectly its neuromodulatory neuroplastic and metaplastic functions, particularly in pathways related to substance-related disorders. Exogenous cannabinoids disrupt these functions. Conclusion: The endocannabinoid system contributes to the definition of setpoints in several neuronal pathways, including pathways critical for the development of substance-related disorders; with Cannabis use these setpoints become more permissive, facilitating Cannabis-related disorders. The advances in understanding the neurobiology of Cannabis open a window of opportunities for new therapeutic strategies in Cannabis-related disorders.

\section{INTRODUÇÃO}

"Orta: - Fazse do pó destas folhas pisadas, e às vezes da semente; (...) o proveito que disto tirão he estar fora de si, como enlevados sem nenhum cuidado e prazimenteiros, e alguns a rir hum riso parvo; (...) os grandes capitães (...) acostumavão embebedar-se com este bangue, pera se esquecerem de seus trabalhos, e nam cuidarem, e poderem dormir."

"Ruano: - (...) esteve bebedo gracioso e nas falas em estremo, e no testamento que fazia (...), porém era triste e grande enjoamento (...) provocava o riso, como o faz hum bebedo saudoso."

Assim discorre Garcia de Orta sobre a boa e a má viagem do bangue, a Cannabis'. Importada para o Ocidente pelo exército napoleônico regressado da África, a Cannabis ganhou maior relevância com Maureau de Tours e a criação do "Club des Hachischins" - associando-se, a partir daí, o uso da Cannabis à criatividade ${ }^{2-4}$. Num contexto de autoexperimentação, Baudelaire escreve que "Les sons se revêtent de couleurs, et les couleurs contiennent une musique" e Gautier "heard the sound of colors, green, red, blue and yellow sounds came in distinct waves $(. . .)^{\prime \prime}$. Contudo, o uso hedonístico e medicinal da Cannabis antecede largamente os períodos históricos supramencionados, recuando até a China na era pré-cristãa,4,7. Entretanto, o seu uso globalizou-se, sobretudo, no século XIX, fenômeno para o qual os descobrimentos portugueses não foram alheios, levando a Cannabis até ao Novo Mundo ${ }^{2,8}$.

Durante séculos os substratos biomolecular, celular e neuroanatômico relacionados ao uso da Cannabis permaneceram inexplicados; tal se acompanhou da demonização do seu uso, com clímax em 1961 na Convenção Única sobre Drogas Narcóticas das Nações Unidas: a Cannabis foi classificada como altamente perigosa e dotada de efeitos nocivos excedentes aos eventuais benefícios terapêuticos, havendo sido comparada a drogas como cocaína e heroína ${ }^{4}$. A descoberta do sistema endocanabinoide (SEC) no final do século XX permitiu uma nova visão sobre o tema, desafiando e revolucionando a até então enraizada visão clássica sobre a Cannabis.

Atualmente, a Cannabis é a droga ilícita mais consumida no mundo, estimando-se os seus consumidores em $4 \%$ da população mundial adulta-14. A dependência, tal como definida pelos critérios da revisão da 4a edição do Manual de Diagnóstico e Estatística das Perturbações Mentais (DSM-IV-TR) e da 10a edição da Classificação Internacional de Doenças e Problemas de Saúde Relacionados (CID-10), estima-se em 10\% da população dos consumidores de Cannabis ${ }^{12,13,15,16}$. Esse valor, bastante inferior ao de outras substâncias de abuso, é alarmante se considerada a elevada prevalência do

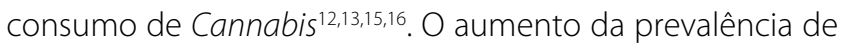
uso e da potência da Cannabis consumida acompanhou-se de aumento nos transtornos por uso de Cannabis (abuso e dependência) $)^{10,14-19}$. Paralelamente, verifica-se uma demanda crescente por estratégias terapêuticas voltadas para esses transtornos, demanda essa que rivaliza em termos absolutos com os das demais drogas de abuso, principalmente cocaína e opiáceos ${ }^{12-16}$. Contudo, as atuais estratégias disponíveis, psicoterápicas e/ou farmacológicas, apresentam eficácia modesta - a maioria dos pacientes falha em obter uma cessação prolongada ${ }^{10,13-15,18,20}$. Assim, este trabalho propõe-se expor o "estado da arte", revendo os conhecimentos sobre o SEC, seu substrato neuroanatômico, biomolecular e celular, descrevendo os mecanismos, pré e pós-sinápticos, de neuroplasticidade dependente dos canabinoides e relacionando-os com a neurobiologia do uso e transtornos por uso da Cannabis. Dessa forma, visa-se entender se é justificado considerar o SEC como um alvo terapêutico potencial para novas abordagens desses transtornos, cuja necessidade transcende a dos debates sobre a regulamentação do uso hedonístico de Cannabis. Reforça-se que esta revisão não se aplica à neurobiologia dos canabinoides para fins medicinais.

\section{MÉTODOS}

\section{Estratégia de busca, identificação e triagem}

Recorreu-se aos motores de busca das bases bibliográficas eletrônicas Medline, Scopus e ISI Web of Knowledge. Na base de dados Medline, fizeram-se quatro pesquisas: 1) "endocannabinoid system" AND ("Receptors, cannabinoid" [MeSH Terms] OR "endocannabinoids" [MeSH Terms]), limitando para artigos 
disponibilizando acesso ao texto integral, escritos em inglês ou português, publicados entre setembro 2000 e setembro 2010, tendo-se obtido 440 artigos; 2) ("neurobiology" [MeSH Terms] AND ("endocannabinoids" [MeSH Terms] OR "Receptors, cannabinoid" [MeSH Terms]), somando 5 artigos; 3) ("endocannabinoids" [MeSH Terms] OR "cannabinoids" [MeSH Terms]) AND ("neuronal plasticity" [MeSH Terms] OR "Long-Term Synaptic Depression" [MeSH Terms] OR "Long-Term Potentiation"), totalizando 171 artigos; 4) ("Cannabis" [MeSH Terms] OR "marijuana abuse" [MeSH Terms] OR "Tetrahydrocannabinol" [MeSH Terms]) AND ("neuronal plasticity" [MeSH Terms] OR "Long-Term Synaptic Depression" [MeSH Terms] OR "Long-Term Potentiation"), perfazendo 31 artigos. Essas pesquisas foram complementadas por outra busca na base de dados Scopus, tendo-se obtido 64 artigos com os critérios "neurobiology" AND "endocannabinoid system", e outra na ISI Web of Knowledge, havendo-se pesquisado por "Topic=(neurobiology) AND Topic=(endocannabinoid)" e obtido 35 artigos.

Dos 746 artigos obtidos, selecionaram-se aqueles cujo título ou resumo correspondia aos objetivos da presente revisão. Como critérios de exclusão, usaram-se: acesso não integral ao artigo, publicação indisponível em língua portuguesa ou inglesa e duplicados. Posteriormente, fez-se pesquisa ativa por artigos relacionados e referências cruzadas, via análise das bibliografias dos artigos obtidos, visando obter bibliografia adicional conforme necessário. Perfizeram-se 80 referências citadas. Consultaram-se ainda o capítulo "Transtornos decorrentes do uso de substâncias psicoativas" do DSM-IV-TR, o capítulo "Transtornos relacionados a substâncias" da CID-10 e os livros Cannabis e saúde mental - uma revisão sobre a droga de abuso e o medicamento, de Zuardi et al. (1 a edição) ${ }^{3}$, Uses of marijuana, de Snyder (1 ${ }^{\text {a }}$ edição) ${ }^{4}$ e Medicinal use of Cannabis: a review, de Hazekamp (2008) ${ }^{7}$.

\section{DISCUSSÃO}

\section{Da Cannabis ao sistema endocanabinoide}

Conhecem-se 538 constituintes da Cannabis spp.7; os fitocanabinoides mais abundantes incluem o delta-nove-tetra-hidrocanabinol ( $\triangle^{9}$-THC), canabidiol, canabinol, canabigerol e canabicromeno ${ }^{21,22}$. Dado serem lipofílicos, atribuíram-se os seus efeitos orgânicos à difusão passiva e à alteração das características membranares neuronais ${ }^{7,23}$. Esse paradigma alterou-se em função de descrições posteriores, pressupondo-se um mecanismo mediado por receptores ${ }^{7,23-25}$. Os análogos do $\triangle^{9}$-THC, quimicamente modificados e marcados radioativamente, constituíram a ferramenta por meio da qual foram identificados os receptores canabinoides $C_{1}$ e $\mathrm{CB}_{2}$ (Cannabinoid binding receptor type 1 e type 2$)^{7,23-26}$. A sua raison d'être não passou despercebida por muito, tendo-se descoberto os ligantes endógenos pouco depois²2.
Essa descoberta gerou uma nova classificação e redefinição dos canabinoides, os quais passaram a englobar os diferentes ligantes dos receptores canabinoides; nomearam-se: endógenos (endocanabinoides), derivados da Cannabis (fitocanabinoides) e sintéticos ${ }^{7}$.

Os receptores canabinoides, respectivos ligantes endógenos e enzimas de produção, transporte e degradação dos endocanabinoides formam o SEC ${ }^{27}$; este constitui um sistema neuromodulatório ubiquitário, fundamental na fisiologia básica e em aspectos comportamentais ${ }^{24,26-36}$. Parece estar envolvido em condições fisiopatológicas em nível central e periférico ${ }^{26}$, tendo sido correlacionado com a dependência ${ }^{27,37}$.

\section{Receptores canabinoides}

Os receptores canabinoides pertencem à superfamília dos receptores acoplados à proteína $\mathrm{G}$, com sete domínios transmembranares $7,24,25,27,29,38,39$. Ligam-se fundamentalmente a proteínas $G_{i / 0}^{7,26,27,29,38,40,41}$, embora interajam com proteínas $G_{s}$ ou $\mathrm{G}_{\mathrm{q}}$ pontualmente ${ }^{26,39}$.

\section{$\mathrm{CB}_{1}$}

Foi demonstrada densidade elevada de $\mathrm{CB}_{1}$ nas camadas internas do bulbo olfativo, hipocampo (sobretudo giro denteado e região (A3), estriado lateral, núcleos estriatais (globo pálido, núcleo entopeduncular, substancia nigra pars reticulata) e cerebelo (camada molecular) 29,38,40,42; densidade moderada no prosencéfalo e alguns núcleos do tronco cerebral e medula espinhal, áreas do córtex cerebral (sobretudo no lobo frontal, parietal e cíngulo), septum, amígdala (núcleo do tracto olfativo lateral), hipotálamo ventromedial, subnúcleo lateral do núcleo interpeduncular, núcleo parabraquial, núcleo do tracto solitário (porção caudal e comissural) e corno dorsal da medula 29,38,40,42; baixa densidade no tálamo e restantes núcleos do tronco cerebral, bem como no corno ventral da medula ${ }^{40,42}$. Verifica-se que os $\mathrm{CB}_{1}$ estão presentes em áreas associadas ao controle motor, resposta emocional, aprendizagem e memória, comportamentos orientados por objetivos, homeostase energética e funções cognitivas superiores, entre outras ${ }^{40,42}$. Nos órgãos e tecidos periféricos os $C B_{1}$ são expressos em baixa densidade ${ }^{26,29}$.

Os CB , são codificados no cromossoma 6q14-q15 pelo gene CNR1 (cannabinoid receptor 1)25,29,42. A sua transcrição/ tradução resulta numa forma longa ou, por splicing alternativo, em duas formas mais curtas que diferem no terminal amina, apresentam diferente capacidade de ligação e têm menor expressão nos tecidos ${ }^{42}$.

Os CB são responsáveis pela maioria dos efeitos psicotrópicos dos canabinoides $23,27,28,38,40-42$. No sistema nervoso central (SNC), localizam-se, sobretudo, pré-sinapticamente $24,25,27-29,38,41$, mas também foram detectados na pós-sinapse e glia ${ }^{25,29,41}$. Constituem o receptor acoplado à proteína G mais abundante no SNC humano, rivalizando com a quanti- 
dade de receptores ionotrópicos glutamatérgicos $7,27,38$. A sua ativação resulta em inibição da adenilciclase, subsequente diminuição da conversão de ATP em AMPc e consequente diminuição da atividade da proteína quinase A (PKA), com diminuição da fosforilação de canais de $\mathrm{K}^{+}$e aumento da saída de $\mathrm{K}^{+}$dos terminais pré-sinápticos ${ }^{7,24,25,27,29,42}$. Independentemente da adenilciclase, inibe canais de $\mathrm{Ca}^{2+}$ sensíveis à voltagem (CCV) tipo $\mathrm{N}$ e P/Q e canais de $\mathrm{K}^{+}$tipo D e M; ativa $G$-protein-gated inwardly-rectifying $K^{+}$channels (GIRK) e canais de $K^{+}$tipo $A^{7,24-27,29,41,42}$. Assim, a ativação $C B_{1}$ gera hiperpolarização neuronal e diminuição da liberação de neurotransmis-

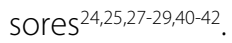

Os $C_{1}$ pós-sinápticos parecem regular a excitabilidade e a plasticidade sináptica via modulação de canais de $\mathrm{K}^{+} \mathrm{e}$ inibição da adenilciclase [com ativação da mitogen activated protein kinase (MAPK) e inibição da PKA] 24,27,38.

\section{$\mathrm{CB}_{2}$}

Os $\mathrm{CB}_{2}$ são expressos, sobretudo, no sistema imunológi$\mathrm{CO}^{7,23-29,38,40,42,43}$. Já foi descrita a presença de $\mathrm{CB}_{2}$ em algumas áreas do SNC26,38, especialmente na microglia e em localização pós-sináptica 7,24,29,41,42. Verificou-se aumento da expressão de $\mathrm{CB}_{2}$ em determinados estados patológicos do $\mathrm{SNC}$, nomeadamente dor crônica ${ }^{24,42}$.

Os $\mathrm{CB}_{2}$ são codificados no cromossoma $1 \mathrm{p} 36$ pelo gene CNR2 (cannabinoid receptor 2) 29,42. Apresenta homologia de $44 \%$ relativamente à sequência aminoacídica do $\mathrm{CB}_{1}{ }^{29,42}$. A sua ativação resulta na atividade de proteínas $G_{i}$ que inibem a adenilciclase, ativando a cascata da MAPK ${ }^{29}$.

\section{Receptores: considerações adicionais}

Discute-se a existência de receptores não $C B_{1} / C B_{2}^{23-26,42}$. Os receptores vaniloides (transient receptor potential vanilloid type 1, TRPV1), filogeneticamente relacionados com receptores canabinoides, constituem os receptores putativos $\mathrm{CB}_{3}^{7,26,40}$. Têm localização pré e, sobretudo, pós-sináptica intracelular ${ }^{23,40,42}$. Estuda-se ainda o papel do receptor GPR55, 7,23,24,26,42 e receptores nucleares do tipo peroxisome proliferator activated receptors a e $\mathrm{\gamma}^{23,26,40}$.

O quadro complexifica-se pela possibilidade de heterodimerização com outros receptores acoplados a proteínas $G$ (nomeadamente receptor metabotrópico dopaminérgico

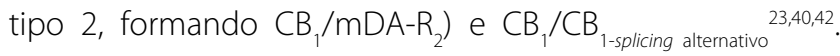
A dimerização poderá ser regulada pelos agonistas e alterar a cascata de sinalização 23,40

Adicionalmente, postula-se que alguns efeitos sejam não específicos, causados por perturbações membranares ${ }^{7,44}$.

\section{Endocanabinoides}

A anandamida (N-araquidoniletanolamida), conjugação de "ananda" (sânscrito para "felicidade eterna") com "amida", foi o primeiro endocanabinoide descoberto; o 2-araquidonilglicerol (2-AG) foi descoberto em seguida ${ }^{7,23-25,27,29,38,41,42,45}$. Os en- docanabinoides descobertos em seguida foram classificados numa dessas duas famílias de compostos ${ }^{7,27}$.

O 2-AG apresenta maior seletividade para os receptores $\mathrm{CB}_{1} / \mathrm{CB}_{2}$ ante a anandamida, a qual também interage com outros receptores 7 . O 2- $\mathrm{AG}$ é agonista total $\mathrm{CB}_{1} / \mathrm{CB}_{2}{ }^{24,26,27,29}$; a anandamida é agonista parcial $\mathrm{CB}_{1} / \mathrm{CB}_{2}$ e agonista total (com baixa afinidade) TRPV124,26,27,29. Embora tenha menor afinidade para os receptores canabinoides ${ }^{29}$, dada a concentração elevada de 2-AG (concentrações 200x superiores à anandamida), este parece ser o principal endocanabinoi$\mathrm{de}^{23-25,29,38,42,45}$.

Os endocanabinoides são uma das exceções à lei da polarização dinâmica, proposta por Ramon e Cajal em 1891, que postula que a comunicação interneural procede dos terminais axonais pré-sinápticos para dendritos pós-sinápticos ${ }^{28,46,47}$; diferentemente dos neurotransmissores clássicos, funcionam como mensageiros retrógados extracelulares, sendo liberados do neurônio pós-sináptico para atuar nos $C_{1}$ pré-sinápticos de forma autócrina e parácri$\mathrm{na}^{7,24,25,28,38}$.

Os endocanabinoides derivam de precursores fosfolipídicos membranares, sendo produzidos sob demanda (sem armazenamento em vesículas sinápticas) nos neurônios pós-sinápticos ${ }^{7,26-28,38,41}$. A síntese é o passo limitante, embora exista elevada redundância nas vias de síntese/inativação ${ }^{7,26}$. Os triggers para a síntese de endocanabinoides são: 1) aumento da concentração intracelular de cálcio $\left[\mathrm{Ca}^{2+}\right]_{i,}$ por despolarização neuronal ou mobilização dos depósitos intracelulares (via estimulação de receptores acoplados a proteínas $\left.\mathrm{G}_{\mathrm{q}} / \mathrm{G}_{11}\right)$; e/ou 2) ativação enzimática direta pelas proteínas $\mathrm{G}_{\mathrm{q}} / \mathrm{G}_{11}{ }^{7}$. Após a síntese são transportados através da membrana celular7; atingem os locais de ligação, situados nas hélices transmembranares dos receptores, difundindo-se lateralmente nos folhetos membranares ${ }^{42}$; o consequente influxo de $\mathrm{Ca}^{2+}$ (via CCV e receptores tipo NMDA, NMDA-R) funciona como segundo mensageiro ${ }^{41}$, modulando a liberação de outros neurotransmissores $\mathrm{s}^{7,38,40}$.

\section{Síntese}

A principal via de síntese de anandamida é a "transacilação-fosfodiesterase": a N-aciltransferase (NAT) converte fosfatidiletanolamina e fosfatidilcolina em $\mathrm{N}$-araquidonilfosfatidiletanolamina (NAPE) ${ }^{23,25-27,41,42,45}$ - a N-acilação da fosfatidiletanolamina constitui o passo limitante ${ }^{26,42}$; segue-se a hidrólise do NAPE pela N-araquidonil-fosfatidil-etanolamina-fosfolipase-D (NAPE-FLD), gerando anandamida23,25-27,41,42,45 (Figura 1).

A NAT é regulada pelo $\mathrm{Ca}^{2+}$ (necessário para a sua ativação) (Figura 1) e AMPc/PKA (atividade enzimática aumentada pela fosforilação) ${ }^{25,42,45}$. A NAPE-FLD está constitutivamente ativa, localizando-se, sobretudo, no retículo endoplasmático dos neurônios pré-sinápticos ${ }^{23,42}$, mas também em pós-sinápticos $39,42,48$. 
Vias alternativas envolvem: FLC-símile/protein tyrosine phosphatase N22 (PTPN22) 23,26,41, alfa-beta-hidrolase-4 (Abh4)/glicerofosfodiesterase GDE1 $23,26,40,49$ e fosfolipase $A_{2} /$ lyso-FLD ${ }^{23,26 .}$

A principal via de síntese do 2-AG é a "FLC $\beta$-DAGL" (fosfolipase C-beta, diacilglicerol-lipase) 23,26,40-42,45 (Figura 2). A FLC $\beta$ converte fosfoinositídeos membranares em 1,2-diacilglicerol; segue-se hidrólise pela DAGL, formando-se 2-AG $23,26,27,40$ 42,45 (Figura 2).

A FLC $\beta$ encontra-se na membrana celular e retículo endoplasmático, sendo ativada via estimulação de receptores glutamatérgicos e muscarínicos associados a proteínas $\mathrm{G}_{q}{ }_{\mathrm{q}}^{26,42}$ (Figura 2). Existem quatro isoenzimas FLC $\beta$ distribuídas desigualmente pelo SNC, associando-se, preferencialmente, cada uma, a um subtipo de receptor ${ }^{26,42}$. Essa via também é $\mathrm{Ca}^{2+}$-dependente ${ }^{26}$ (Figura 2).

Vias alternativas envolvem: fosfolipase $A_{1} / F L C$-liso-inositolfosfato-específica, lipase hormonossensível e uma fosfatase de lipídeos $23,42,45$.

A ativação de TRPV1 pós-sinápticos pela anandamida poderá constituir um mecanismo de feedback regulatório, inibindo a DAGLa e diminuindo a produção de 2-AG 23,40 .

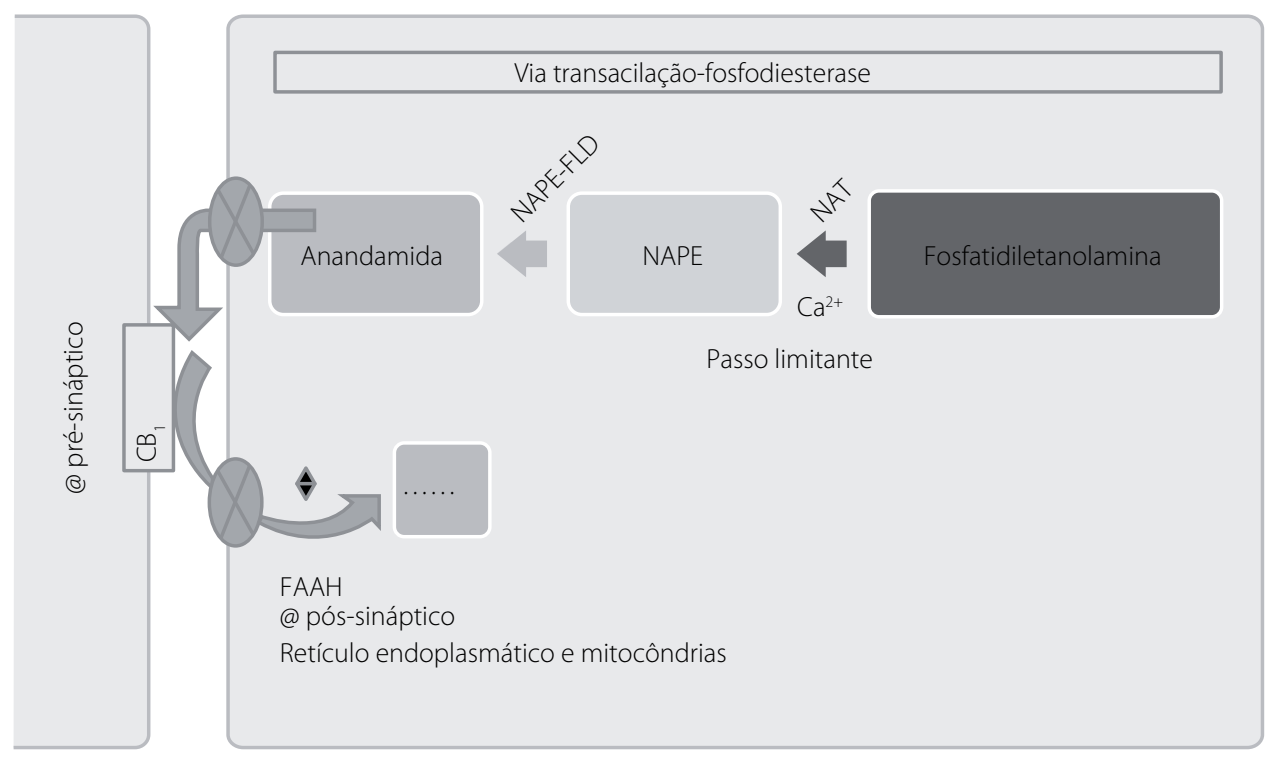

Figura 1. Síntese e inativação da anandamida.

$\mathrm{Ca}^{2+}$ : cálcio; FAAH: fatty acid amide hydrolase; NAPE-FLD: N-araquidonilfosfatidiletanolamina fosfolipase D; NAT: N-aciltransferase.

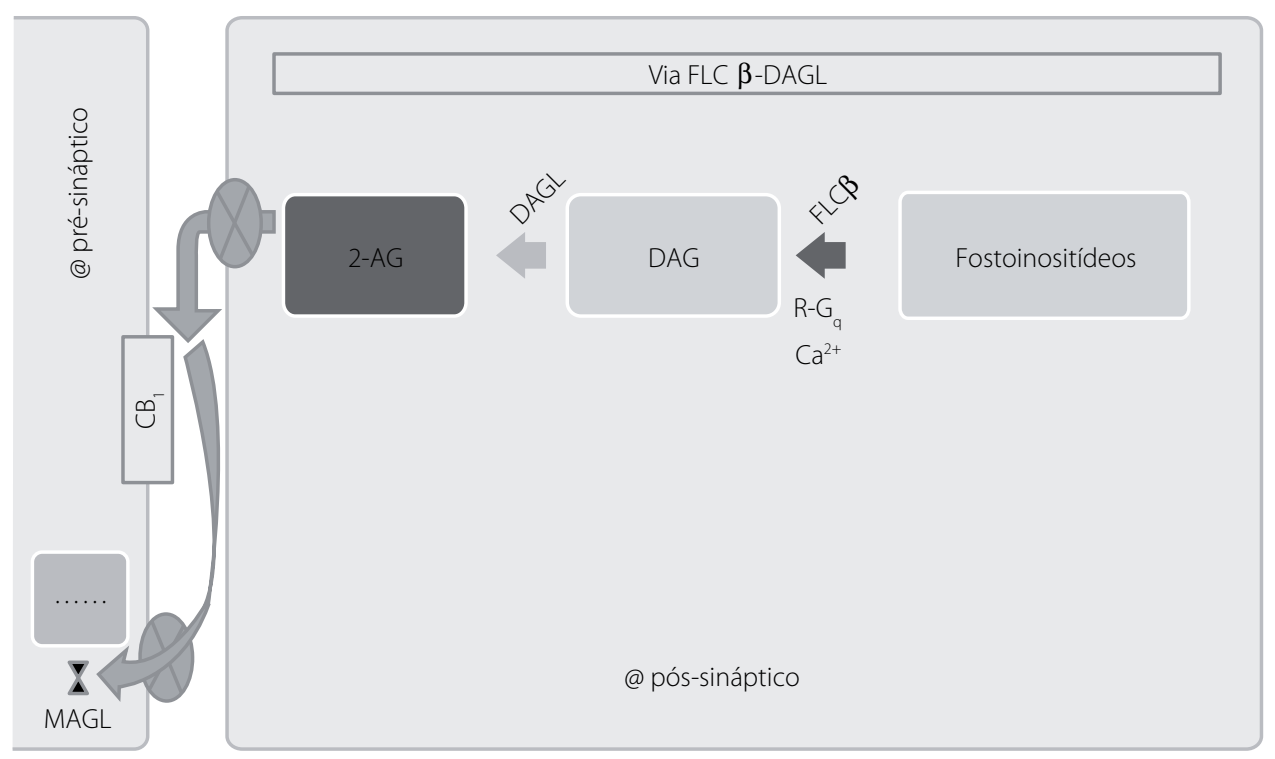

Figura 2. Síntese e inativação de 2-AG.

$\mathrm{Ca}^{2+}$ : cálcio; DAGL: diacilglicerol-lipase; FLCß: fosfolipase C beta; MAGL: monoacilglicerol-lipase; R-Gq: receptor metabotrópico acoplado à proteína Gq. 


\section{Transporte}

O transporte da anandamida e 2-AG através das membranas neuronais é similar e ocorre por um processo sugestivo de difusão facilitada mediada por transportadores ${ }^{25,38,45}$.

\section{Inativação}

A inativação envolve: 1) captação pré-sináptica ou recaptação pós-sináptica; 2) oxidação ou hidrólise rápida das ligações amida/éster ${ }^{23,42}$.

A principal enzima responsável pela metabolização da anandamida é a fatty acid amide hydrolase (FAAH), encontrada, sobretudo, nos compartimentos intracelulares (retículo endoplasmático, mitocôndrias) de neurônios pós-sinápticos (Figura 1), mas também na glia ${ }^{23-25,27,40-42,45}$. A inativação do 2-AG ocorre nos neurônios pré-sinápticos, por hidrólise pela monoacilglicerol-lipase (MAGL) (Figura 2), com potencial participação da FAAH e alfa/beta-hidrolase-6 e -12 (abh6/12) 23,27,40-42. A cicloxigenase-2 (COX-2), a lipoxigenase-12 e -15 (LOX-12/-15) e as oxigenases do citocromo p450 podem inativar ambos ${ }^{23,42}$. A COX-2 localiza-se pós-sinapticamente e tem maior afinidade pelo 2-AG, podendo regular a quantidade de 2-AG liberado ${ }^{42,50}$.

\section{Do SEC à neuroplasticidade}

O SEC relaciona-se intimamente com fenômenos de neuroplasticidade, nomeadamente depressão a curto prazo (endocannabinoid short-term depression, EC-STD) e a longo prazo (endocannabinoid long-term depression, EC-LTD) 24,27,28,38,39,42.

\section{EC-STD/-LTD: mecanismos pós-sinápticos}

A EC-STD subclassifica-se em: a) supressão da inibição/excitação induzida pela despolarização (depolarization-induced suppression of inhibition/excitation, DSI/DSE), conforme induzida em neurônios inibitórios/excitatórios 24,27,28,38,39,42,47,51-55; b) supressão mediada por receptores ionotrópicos NMDA (NMDA-R-EC-STD) ${ }^{39,42}$; c) supressão mediada por receptores metabotrópicos (metabotropic-induced suppression of inhibition/excitation, MSI/MSE) ${ }^{24,38,39,42}$; sobretudo receptores metabotrópicos glutamatérgicos tipo 1 e tipo $5\left(m G l u-R_{1} /-R_{5}\right)$ e receptores metabotrópicos colinérgicos muscarínicos tipo 1 e tipo 3 (mAChR-M ( $\left._{1} / \mathrm{M}_{3}\right)^{38,39,42}$.

Os mecanismos pós-sinápticos da EC-STD são:

1) Via FLC $\beta$-independente: aumento isolado da $\left[\mathrm{Ca}^{2+}\right]_{i}$ (Ca ${ }^{2+}-$ mediado), via CCV na DSI/DSE 24,28,38,41,42,47,53,55 ou NMDA-R na NMDA-R-EC-STD ${ }^{42}$, ocasionalmente com contribuição da mobilização de reservas intracelulares de $\mathrm{Ca}^{2+38,42}$. O mediador pode ser o 2-AG ou outro endocanabinoide $28,38,39,42,55$.

2) Via FLC $\beta$-dependente: induzida por ativação de receptores metabotrópicos acoplados a proteínas $G_{q / 11}$ perante níveis basais ou aumentados da $\left[\mathrm{Ca}^{2+}\right]_{\mathrm{i}}$ (metabotrópico-mediado e comediado, respectivamente) ${ }^{24,38,39,41,42,53}$. A ativação dos receptores/ $G_{q / 11}$ estimula a via FLCB/DAGL-dependente $\mathrm{te}^{38,39,41,42}$, gerando 2-AG $38,39,41,42$.
Note-se que o mecanismo $\mathrm{Ca}^{2+}$-mediado pode ser potenciado pela ativação de receptores acoplados a proteínas $G_{q / 11}^{41,55}$. Paralelamente, o mecanismo metabotrópico-mediado requer maior concentração do agonista do que o comediado ${ }^{42}$. Isso traduz um sinergismo, hipotetizando-se que haja: 1) otimização do mecanismo $\mathrm{Ca}^{2+}$-mediado por ativação de receptores acoplados a $\mathrm{G}_{q / 11} 28,38,42,47$, conduzindo à ativação da FLC, produção de inositol-trifosfato e mobilização dos depósitos intracelulares de $\mathrm{Ca}^{2+47}$; e/ou 2) aumento da $\left[\mathrm{Ca}^{2+}\right]_{i}$ otimizando as cascatas associadas ao mecanismo metabotrópico ${ }^{38,42,47}$. A ativação da FLC $\beta$, por ser induzida por receptores $/ G_{q / 11}$ e $\mathrm{Ca}^{2+}$-dependente, serve como "detector de coincidência", integrando a ativação metabotrópica com a elevação da $\left[\mathrm{Ca}^{2+}\right]_{i}^{38,39,42}$.

A EC-LTD subclassifica-se em: a) LTD; b) LTD of inhibitory synapse (LTDi) ou LTD-heterossináptica; C) dependente da temporização de disparo (spike-timing-dependent LTD, LTDt); d) LTD pós-sináptica; e) autoinibição lenta24,27,36-39,41,48,51,56-62.

Os mecanismos pós-sinápticos da EC-LTD são semelhantes aos da EC-STD (i.e., $\mathrm{Ca}^{2+}$-mediado, metabotrópico-mediado e comediado ${ }^{28,37,38,48,60,63}$. O mecanismo metabotrópico-mediado é efetivado pelo 2-AG ${ }^{38,48,63}$, com duas exceções. Na amígdala, a ativação de receptores metabotrópicos glutamatérgicos de grupo I (mGluR-I) estimula a via adenilciclase/PKA originando anandamida ${ }^{38,48}$. Nas vias corticoestriatais, há formação de anandamida mediada por mDA- $R_{2}$ associados a $G_{1 / 0}{ }^{48}$. Dois modelos explicam o último caso; no modelo "indireto" a ativação mDA- $R_{2}$ ocorre em interneurônios colinérgicos, suprimindo o disparo dos interneurônios, consequentemente diminuindo a liberação de acetilcolina e o tônus mAChR-M $\mathrm{M}_{1}$ a aumentará subsequentemente a atividade de canais de $\mathrm{Ca}^{2+}$ tipo $\mathrm{L}$ e o influxo de $\mathrm{Ca}^{2+}$, otimizando a síntese de endocanabinoides ${ }^{42,48}$; no modelo "direto" a ativação mDA-R $R_{2}$ ocorre nos neurônios glutamatérgicos, potencializando a síntese de endocanabinoides ${ }^{42,48}$.

Na maioria das regiões encefálicas [estriado dorsal, núcleo Accumbens (NAc), cerebelo, córtex pré-frontal (CPF), córtex sensorial], predomina o mecanismo comediado $38,48,55$.

O mecanismo metabotrópico-mediado parece suficiente na indução de LTDi no hipocampo e amígdala, embora fisiologicamente seja mais provável um mecanismo comediado $38,42,51$

Na LTDt, a relação temporal (janela temporal da ordem de milissegundos ${ }^{48}$ ) entre atividade pré-/pós-sináptica determina a direção (depressão ou potenciação) e a magnitude da mudança na força sináptica24,38,39,42. Segundo a Lei de Hebb, padrões pré-para-pós condicionam potenciação a longo prazo (endocannabinoid-independent spike-timing-dependent long-term potentiation, EC-independent LTPt), enquanto padrões pós-para-pré condicionam EC-LTD 24,38,39,42. Ilustrando: os neurônios pré-sinápticos despolarizados por um estímulo $A$ ativam o neurônio pós-sináptico conduzindo à síntese de endocanabinoides que atuam nos pré- 
-sinápticos; se nesse momento (ou pouco após) esses pré-sinápticos se despolarizam em virtude de um estímulo B, será necessário deprimir essa transmissão sináptica de forma a não se misturarem os estímulos.

Genericamente, a LTDt consiste em mecanismo comediado com liberação de endocanabinoides e ativação pré-sináptica coincidente dos $C_{1}$ e NMDA-R (pelos endocanabinoides e pelo glutamato liberados dos neurônios pós-sináptico e pré-sinápticos, respectivamente) 27,38,42,48,57.

Esse paradigma tem exceções: foi descrito no núcleo coclear dorsal uma LTDt anti-hebbiana em que o padrão pré-para-pós condiciona LTD (que se sobrepõe à potenciação de longo prazo, LTP) ${ }^{38,42,58}$. O mecanismo é $\mathrm{Ca}^{2+}$-mediado (via ativação coincidente pós-sináptica de NMDA-R e CCV ativados por despolarização) e terá a anandamida como mediador ${ }^{38}$.

Genericamente, a LTD é habitualmente induzida no neurônio pós-sináptico e expressa no pré-sináptico (por diminuição da liberação de neurotransmissor); no cerebelo ela é induzida e expressa na pós-sinapse, embora requerendo sinalização endocanabinoide retrógada ${ }^{38,42,48}$. O modelo proposto é: 1) indução no neurônio pós-sináptico; 2) sinalização retrógada endocanabinoide com ativação de $\mathrm{CB}_{1}$ pré-sinápticos e liberação de sinal anterógrado (possivelmente óxido nítrico) ${ }^{38,39,41,42,48,59}$. Há convergência pós-sináptica dos três sinais (influxo de $\mathrm{Ca}^{2+}$, ativação mGluR-I - conjuntamente representando mecanismo comediado - e óxido nítrico) com ativação da proteína quinase C (PKC), fosforilação da subunidade mGlu- $\mathrm{R}_{2}$ dos a-amino-3-hydroxy-5-methyl-4isoxazolepropionic acid receptor (AMPA-R) e endocitose dos AMPA-R-fosforilados $38,42,59$.

Outra exceção é a autoinibição lenta. Despolarizações pós-sinápticas repetitivas produzem endocanabinoides que atuam de forma autócrina nos $\mathrm{CB}_{1}$ pós-sinápticos, promovendo condutância prolongada ao $\mathrm{K}^{+}$e hiperpolarização gerando autoinibição de longo prazo ${ }^{24,39,56}$. Assim, a LTD é induzida e expressa no pós-sináptico (por redução da excitabilidade), sem sinalização retrógada.

\section{EC-STD/-LTD: mecanismos pré-sinápticos}

Dada à similaridade nos mecanismos pós-sinápticos básicos da EC-STD/LTD, atribui-se a indução diferencial desses processos a diferentes mecanismos pré-sinápticos ${ }^{63,64}$. Efetivamente, ambos requerem ativação $C B_{1}$, mas diferem na quantidade/duração dos endocanabinoides liberados ${ }^{38,42,48,63}$. $O$ padrão temporal diferencial na ativação $\mathrm{CB}_{1}$ (mais prolongado na indução de LTD) pode ser responsável por diferenças nas vias intracelulares mobilizadas: subunidades $G_{\beta \gamma}$ na EC-STD 28,38,42,48,55; braço efetor Gi na EC-LTD 42,48,55,64.

A EC-LTD requer alterações que transformem a depressão transitória mediada pela ativação $\mathrm{CB}_{1}$ numa depressão persistente $\mathrm{CB}_{1}$-independente ${ }^{38,48,63}$; assim, as repercussões intracelulares da ativação $C_{1}$ tornam-se mais duradouras que a ativação ${ }^{38,42,48}$. Portanto, $\mathrm{O} C \mathrm{CB}_{1}$ é necessário à in- dução, mas não à manutenção de LTD, e pode ser insuficiente à indução se forem requeridos outros sinais (e.g. despolarização ou ativação coincidente de NMDA-R pré-sinápticos) ${ }^{27,28,38,41,42,48}$.

$\mathrm{Na}$ EC-STD, a ativação dos $\mathrm{CB}_{1}$ pré-sinápticos induz a inibição de CCV, ativação de GIRK (por interação direta com subunidades $\beta \gamma)^{25,28,55}$ e/ou efeito inibitório direto na maquinaria de exocitose vesicular 28,38 .

Para a EC-LTD, existem três modelos pré-sinápticos propostos ${ }^{48}$. Num deles a diminuição da PKA provoca alterações no balanço fosforilação/desfosforilação; a diminuição da fosforilação de RIM1a (e de outras proteínas da maquinaria de exocitose) causa diminuição da sua atividade, diminuindo a liberação de neurotransmissores ${ }^{42,48,64,65}$. Os outros modelos apontam para redução PKA-dependente do influxo de $\mathrm{Ca}^{2+}$ via CCV tipo $\mathrm{P} / \mathrm{Q}^{48,65}$ e redução da excitabilidade pré-sináptica motivada pela ativação de canais de $\mathrm{K}^{+48}$.

\section{EC-STD/-LTD: mecanismos de terminação}

A magnitude e o curso temporal da EC-STD são determinados pelo balanço entre produção pós-sináptica e metabolização pré-/pós-sináptica de 2-AG ${ }^{42}$. A atividade da MAGL é crucial para a terminação da EC-STD ${ }^{42}$. A COX-2 pós-sináptica contribui para essa regulação $0^{42}$. Não há evidência de que a FAAH contribua para a terminação da EC-STD ${ }^{42}$. O papel de outras enzimas é desconhecido ${ }^{42}$.

O processo de "des-depressão" da LTD é obscuro, desconhecendo-se se ocorre espontaneamente ou por mecanismo ativo 38,48 .

\section{Metaplasticidade endocanabinoide-mediada}

Além da indução de EC-STD/LTD, os endocanabinoides estão envolvidos em processos de metaplasticidade, i.e., modificação a longo prazo do limiar de indução de plasticidade28,38,41,42,48. Os mecanismos são: 1) supressão de LTP-endocanabinoide-independente por interferência na cascata da PKA, a qual está envolvida na plasticidade endocanabinoide-dependente/-independente ${ }^{33,38,42}$; 2) potenciação de LTP excitatória durante EC-STD inibitória/LTDi (por alteração da excitabilidade pós-sináptica, desinibição local e "priming" seletivo das sinapses excitatórias vizinhas, facilitando a indução de LTP nessas sinapses) ${ }^{28,38,41,42,48,50,51,61 .}$.

\section{Do sistema endocanabinoide/neuroplasticidade aos modelos de transtorno por uso de substâncias}

Como contribui a plasticidade sináptica e sua modulação para a modificação comportamental? Como são alteradas pelos canabinoides exógenos e quais as suas consequências no âmbito do uso, uso abusivo e dependência?

Em termos de distribuição neuroanatômica, celular e biomolecular, o SEC adequa-se às funções de modulação do humor, da recompensa e comportamentos orientados por 
objetivos (goal-oriented behaviors), da cognição e percepção $0^{37,40}$, sendo central na fenomenologia dos transtornos por uso de substâncias 9,37,40.

\section{Visão clássica e circuito do prazer}

A visão clássica da dependência enfatiza o sistema dopaminérgico mesocorticolímbico de recompensa (circuito do prazer), representando os transtornos por uso de substâncias uma desregulação dos substratos neuroanatômicos de recompensa ${ }^{40,66}$. O circuito é constituído por: ventral limbic forebrain loci (VLFL), área tegmental ventral (ATV), feixe prosencefálico medial (FPM), NAc, pálido ventral (PV) e CPF medial9,67,68. Essas estruturas estão interconectadas por neurônios de primeira ordem (VLFL para ATV), segunda ordem (neurônios dopaminérgicos entre ATV e NAc-FPM) e terceira ordem (NAc para estruturas relacionadas com expressão de comportamentos relacionados com recompensa) ${ }^{9,67,68}$; recebe adicionalmente numerosos inputs modulatórios dos sistemas opioide, serotoninérgico, GABAérgico e glutamatérgico; os dois últimos sendo particularmente importantes na regulação dos processos de recompensa e comportamentos associados ${ }^{67,68}$. Esse circuito codifica o tônus hedônico, a expectativa de recompensa e sua desconfirmação, a priorização de recompensas e outros aspectos complexos de aprendizagem/motivação relacionados à recompensa ${ }^{68}$.

O circuito do prazer evoluiu para reforçar respostas de recompensa a estímulos naturais biologicamente essenciais 967,68 . A sua ativação por drogas de abuso constitui um sequestro farmacológico das funções normais de recompensa cerebral (por constituírem estímulos mais potentes) ${ }^{9,66-68 ;}$ a sua (sobre)ativação correlaciona-se com comportamentos de procura e uso de drogas (drug-seeking e drug-taking $)^{40,67,68}$.

\section{Predisposição e circuito do prazer}

A vulnerabilidade inicial e a recaída são conferidas por fatores genéticos, uso da droga e características (disfóricas) da abstinência ${ }^{67,68}$, envolvendo: 1) diminuição de função do eixo ATV-NAc ${ }^{67,68}$ e 2) aumento da concentração do fator de liberação da corticotropina no núcleo central da amígdala ${ }^{67,68}$. A combinação de diminuição da recompensa induzida pela droga, aumento dos processos antagônicos nas estruturas de recompensa e recrutamento do sistema neuronal de estresse na amígdala providencia a mudança alostática no setpoint de tônus hedônico, promovendo comportamentos de procura e uso $0^{67,68}$.

\section{Sistema endocanabinoide e circuito do prazer}

Em termos gerais, as drogas de abuso ativam o circuito do prazer por meio dos neurônios dopaminérgicos de segunda ordem do eixo ATV-NAc, por ação direta nos terminais dopaminérgicos ou indiretamente sob os inputs modula- tórios ${ }^{35,67,68}$. Atualmente se aceita que os canabinoides exógenos ativem a via de recompensa de forma semelhante a outras drogas de abuso, embora provavelmente diferindo nos mecanismos celulares intervenientes $9,35,67,68$. Como? Os endocanabinoides contribuem para a homeostase motivacional por meio da definição de um setpoint ${ }^{40}$; os canabinoides exógenos levam à perturbação da homeostase motivacional por desestruturação neuromodulatória e alteração do setpoint desse circuito $35,66,67$.

Atente-se para isso nos modelos de regulação endocanabinoide do tônus de recompensa na ATV e no NAc. No primeiro caso, a modulação dopaminérgica do eixo ATV-FPM-NAc deve-se à ação direta dos endocanabinoides em neurônios dopaminérgicos na ATV, dupla desinibição GABAérgica (ação indireta nos circuitos inibitórios intrínsecos/locais da ATV e ação indireta nas projeções inibitórias extrínsecas do NAc para ATV), contrapondo-se à ação indireta nos inputs extrínsecos excitatórios (inibição glutamatérgica) $)^{35,40,66,67,69,70}$ (Figura 3). Dessa forma, o SEC modula o balanço de inputs excitatórios/inibitórios na ATV, nomeadamente as contribuições GABAérgica intrínseca e extrínseca, glutamatérgica e opioide ${ }^{40,66,67,69,70}$. A colocalização especulativa de $\mathrm{CB}_{1}$ com receptores opioides $\mu$ (ROM) nos interneurônios inibitórios justificaria o bloqueio dos efeitos do $\Delta^{9}$-THC pelos antagonistas opioides, observado experimentalmente $18,40,67,70$.

$A$ ativação $C B$, pode ser relevante apenas nas circunstâncias apropriadas de atividade GABAérgica e glutamatérgica em determinados contextos comportamentais específi$\cos ^{67,70}$ (Figura 3). Similarmente, a ativação de inputs opioides endógenos pode requerer estímulos ambientais ou comportamentais específicos ${ }^{67,70}$. Isso significa que o resultado final será dependente do set (contexto interior) e setting (contexto ambiental) (Figura 3). Dessa forma, pode-se entender as diferentes consequências associadas ao uso terapêutico ou hedonístico da Cannabis, incluindo a transição (ou não) de uso experimental para hedonístico e os diferentes padrões de uso recreacional ${ }^{71}$.

A modulação dopaminérgica do eixo ATV-FPM-NAc no NAc ocorre de forma bastante similar, podendo ocorrer modulação direta e indireta ${ }^{40,67,69,70}$. Esta última surge via inibição dos medium-spiny-neurons (MSN) GABAérgicos do NAc, por desinibição dos neurônios GABAérgicos intrínsecos e/ou dos colaterais recorrentes dos MSN, contrapondo-se à inibição

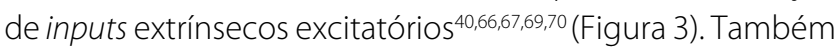
no NAc pode ocorrer interação canabinoide-opioide/-dopaminérgica, dada a colocalização $C B_{1}$ com $R O M$ e mDA- $R_{2}$ e a possibilidade de formação de heterodímeros $\mathrm{CB}_{1} / \mathrm{mDA}$ $-R_{2}{ }^{40,70}$. Assim, o SEC modula o balanço de inputs excitatórios/ inibitórios dos MSN do NAc e outputs GABAérgicos para a ATV66,67,69,70 (Figura 3).

Portanto, observa-se uma inter-relação entre SEC, sistemas dopaminérgico e opioide nas diferentes localizações ${ }^{72}$. 


\section{Visão da neuroplasticidade estriatal}

Com o avançar da investigação científica, a visão clássica evoluiu para um conceito mais abrangente dos transtornos por uso em que a desregulação do controle motivacional se associa à desregulação da formação de hábitos ${ }^{37,67}$, por envolvimento, além do estriado ventral, do estriado dorsal (região relacionada à formação de hábitos, planejamento motor e aprendizagem motora induzida pela recompensa) ${ }^{37,67}$. Essa visão enfatiza a modulação da plasticidade sináptica estriatal globalmente, incluindo circuito ATV-FPM-NAc e neoestriado dorsal ${ }^{37,67}$; os transtornos por uso constituem-se como um processo de aprendizagem mal-adaptativo/patológico, envolvendo sinalização neuronal e mecanismos sinápticos, sobretudo fenômenos de plasticidade a longo prazo $33,37,60$.

Assim, as drogas de abuso usurpam os mecanismos de regulação motivacional/recompensa conduzindo a comportamentos de busca e uso de drogas ${ }^{37,70}$. A modulação da plasticidade sináptica a longo prazo nos circuitos envolvidos constitui uma forma de as consequências comportamentais serem reforçadas, por usurpação dos mecanismos de aprendizagem normais, constituindo processos de aprendizagem anormais ${ }^{33,37,60}$ e cimentando respostas comportamentais relacionadas ao comportamento de busca $37,66,70,73$. Alguns indivíduos progridem para uma aprendizagem baseada em hábitos (habit-based learning), suficientemente forte a ponto de persistir perante evidência de consequências pessoais adversas ${ }^{37}$.

Ou seja, o circuito do prazer medeia as alterações neuronais iniciadas pelas drogas de abuso, por sobreativação dos mecanismos de recompensa e sensibilização comportamental a exposições repetitivas ${ }^{37,66}$. As alterações no funciona- mento do NAc facilitam a plasticidade sináptica no estriado dorsal (por influência sobre fluxo de informação por meio dos gânglios da base) $)^{37}$, o qual está envolvido em fases avançadas do transtorno por uso; nelas o uso progride para patologia compulsiva/impulsiva e estreitamento do repertório comportamental, dirigido sobretudo à busca pela droga ${ }^{37,67}$. A plasticidade sináptica de longo prazo em ambos os processos/fases representa o substrato pelo qual as drogas de abuso induzem as alterações comportamentais persistentes características dos transtornos por uso 35,37,60,66.

A progressão ventral para dorsal da alteração funcional estriatal durante o curso de uso de drogas explica a evolução dos comportamentos de busca para comportamentos centrados na substância de abuso ${ }^{37,67}$. Esse processo contínuo de alostase constitui o modelo conceptual mais aceito no entendimento atual das dependências ${ }^{37}$. Nele, o downward spiral clínico tem paralelismo na progressão neuroanatômica, traduzindo-se pela evolução de reward-driven drug-taking para non-rewarding habit-driven drug-taking, transicionando-se de uso hedônico para dependência ${ }^{37,66,67}$.

\section{Sistema endocanabinoide e neuroplasticidade estriatal}

A inter-relação SEC/plasticidade sináptica e sistema dopaminérgico não se limita ao circuito do prazer ${ }^{9,37,69,74}$. Devem-se considerar mecanismos indiretos de modulação do balanço de inputs inibitórios/excitatórios ${ }^{9,69}$, mecanismos diretos por colocalização $\mathrm{CB}_{1}$ e mDA-R $2^{\prime}$ sinergismo na LTDi na ATV e $\mathrm{CPF}^{74}$ - via crosstalk nas cascatas de sinalização e/ou formação de heterodímeros $\mathrm{CB}_{1} / \mathrm{mDA}-\mathrm{R}_{2}{ }^{74}$ - e ativação TRPV1 em

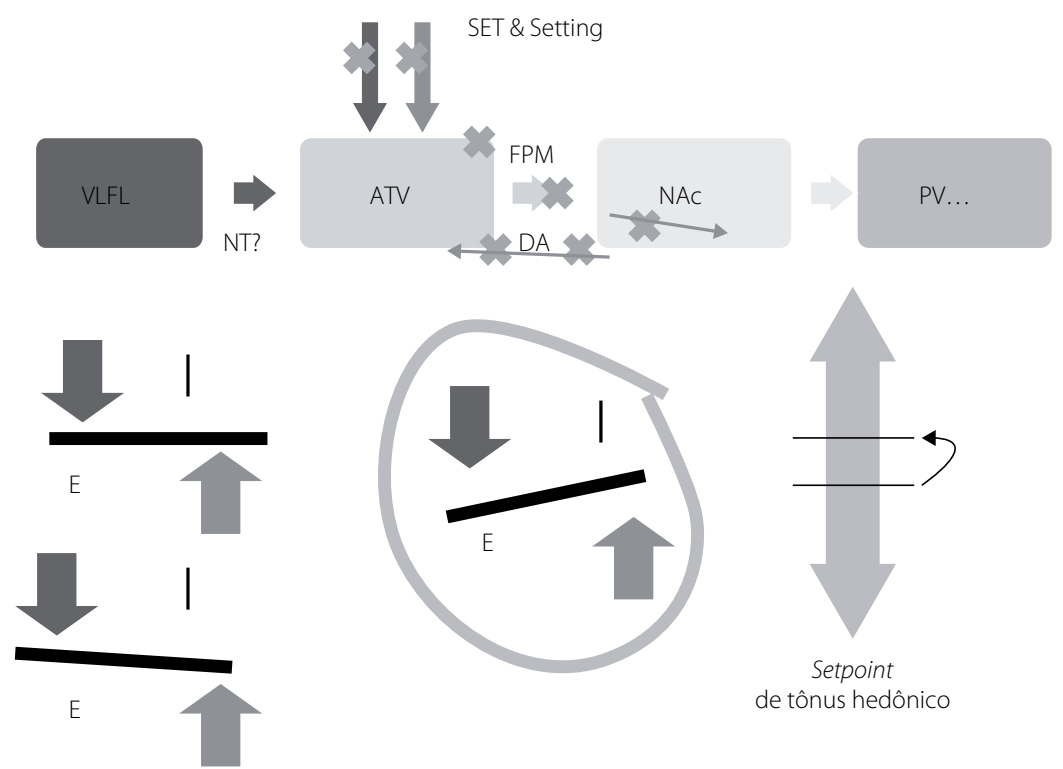

Figura 3. Efeito da plasticidade sináptica dependente de canabinoides no output do sistema mesocorticolímbico de recompensa. Os contextos interno (set) e ambiental (setting) influenciam as aferências modulatórias, com impacto no balanço final do sistema. Se o output excitatório prevalecer, verifica-se aumento do setpoint de tônus hedônico.

VLFL: ventral limbic forebrain loci; VTA: área tegmental ventral; FPM: feixe prosencefálico medial; NAc: núcleo accumbens; NT?: neurotransmissor a esclarecer; DA: dopamina; PV...: pálido ventral e outros; E: componente excitatório; I: componente inibitório. 
neurônios dopaminérgicos por canabinoides derivados de eicosanoides ${ }^{69}$. Dessa forma, o SEC parece regular o disparo e o padrão de atividade dos neurônios dopaminérgicos por meio do controle retroativo dos inputs inibitórios/excitatórios ${ }^{9,37}$. Paralelamente, no estriado dorsal o SEC surge como detector de coincidência de atividade sináptica coordenada, dopaminérgica e glutamatérgica, resultando em indução de LTD $^{9,37}$. Portanto, ocorre uma regulação bidirecional ${ }^{9,37,69}$.

As flutuações na liberação de dopamina pela ATV (por antecipação de recompensa ou farmacologicamente induzida) podem alterar as funções de capacidade sináptica no sentido de produzir alterações no comportamento, promovendo a escolha de uso da substância ${ }^{37,67}$. Também no neoestriado, a dopamina e certos padrões de atividade dopaminérgica parecem estar envolvidos na neuroplasticidade a longo prazo, com indução de LTP pela ativação dopaminérgica fásica ou LTD pela ativação dopaminérgica tônica ${ }^{37,67,74}$.

Sendo assim, a dopamina tem um papel na otimização da aprendizagem associativa dos comportamentos reforçados, pela influência sobre a excitabilidade sináptica e facilitação de plasticidade sináptica ${ }^{37}$. Enquanto isso, o SEC foi proposto como um mediador entre impulso de consumo (craving) e satisfação; a sua disfunção associar-se-ia a uma maior discrepância entre o estado psicológico desejado e o obtido ${ }^{75}$. Porém, postulamos que não se deve desprezar a influência do SEC em outros sistemas, os quais poderão ser cruciais para a persistência da dependência. Além das repercussões em áreas relacionadas com recompensa (NAC e ATV) e formação de hábitos (estriado dorsal), envolve-se na memória/aprendizagem (hipocampo), emoções básicas e memória emocional (amígdala) e inibição, autocontrole e planeamento comportamental (CPF) 9,25,31-37,66,75 (Figura 4).

Por exemplo, a presença do SEC em áreas relacionadas com a memória e o seu papel na modulação dela é bastante relevante, facilitando a extinção e inibindo a consolidação de memórias aversivas ${ }^{28,30-36}$. A interferência exercida sobre esse sistema pelo $\triangle^{9}$-THC, bloqueando a LTD e, assim, modificando o setpoint para extinção de memórias aversivas, pode alterar o impacto de memórias relacionadas com a recompensa $9,30,32,36,73,76$. Assim, as ações dos canabinoides exógenos
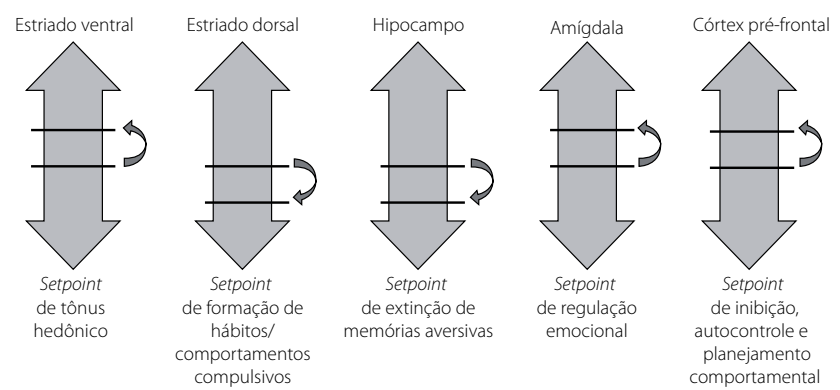

Figura 4. Alteração de setpoints nos transtornos por uso de Cannabis. Setpoints aumentados correspondem à maior dificuldade para atingir o alvo; setpoints diminuídos permitem maior facilidade de atingir o alvo. não se limitam ao mero papel de reforçadores positivos por ativação do sistema dopaminérgico mesocorticolímbico, mas são de extrema relevância na fenomenologia da dependência ao induzirem setpoints mais permissivos em diversas vias neuronais (Figura 4).

\section{$\Delta^{9}$-THC/Cannabis e sistema endocanabinoide}

Como se relaciona o principal componente psicoativo da Cannabis, $\triangle^{9}-\mathrm{THC}^{24,25}$, com as múltiplas formas de plasticidade sináptica?

Hipótese 1 - Sendo um agonista $\mathrm{CB}_{1}, 0 \Delta^{9}$-THC mimetiza as ações dos endocanabinoides, mas o faz difusamente (violando a especificidade espacial), inibindo a transmissão sináptica por meio da ativação indiscriminada dos receptores $^{24,27,39}$. Contrariamente à especificidade temporal e espacial dos endocanabinoides, o $\triangle^{9}$-THC (pré-formado) viola os mecanismos de especificidade espacial para a síntese de endocanabinoides (cooperação pós-sináptica com integração de sinais pela FLCß e, dada a localização subcelular diferencial da maquinaria sintética, colaboração para mobilização dessa maquinaria). Esse modelo não se aplica nos casos que impliquem cooperação pré-sináptica, e.g., ativação coincidente de $C_{1}$ e NMDA-R pré-sinápticos, pois essa não é violada.

Hipótese 2 - Sendo um agonista parcial $\mathrm{CB}_{1}, \mathrm{O} \Delta^{9}$-THC antagoniza os efeitos de endocanabinoides de alta eficácia (2-AG) e mimetiza efeitos de endocanabinoides de baixa eficácia (anandamida) 24,27,39,77. Diversos casos de antagonismo pelo $\triangle^{9}$-THC foram descritos $24,27,77-39,76,77$. Adicionalmente, a administração aguda ou crônica de $\triangle^{9}$-THC induz a tolerância de receptores $\mathrm{CB}_{1}$ e tolerância cruzada para $\mathrm{ROM}$ no NAC, induzindo bloqueio de LTD/LTP29,37,38,42,76,78. A administração crônica de Cannabis pode levar à tolerância e à tolerância inversa/sensibilização comportamental, contribuindo para a apetência e a motivação aumentadas pela substância ${ }^{40,79}$. A tolerância pode não se desenvolver nos padrões habituais de uso social de Cannabis, mas apenas no caso de uso intenso ${ }^{79}$. A administração prolongada produz tolerância para a maioria dos efeitos farmacológicos, devendo-se essencialmente a respostas farmacodinâmicas (downregulation e dessensibilização dos $\left(B_{1}\right)$, embora existam evidências de contribuições menores por fenômenos farmacocinéticos (absorção, biodisponibilidade, distribuição, metabolismo e excreção) e de adaptação de subpopulações neuronais específicas ${ }^{29,79}$. A tolerância mostra marcada dependência regional, indicativa de diferentes mecanismos de regulação e diferenças na eficiência dos sistemas efetores acoplados aos $\mathrm{CB}_{1}{ }_{1,40,79}$, tal que um melhor acoplamento resulta em maior resistência a alterações adaptativas ${ }^{79}$. A tolerância inversa permanece em estudo, mas pode envolver upregulation ${ }^{29}$.

Assim, os canabinoides exógenos têm um papel no comprometimento da neuromodelação mediante alteração do desempenho dos receptores e das cascatas de sinalização intracelulares. 
Hipótese 3 - Postulamos uma sinergia dos elementos de cada uma das hipóteses anteriores, as quais não são mutuamente exclusivas.

Dentre as sinapses que expressam $\mathrm{CB}_{1}$, as inibitórias geralmente têm densidade mais elevada de $\mathrm{CB}_{1}$ do que as excitatórias $^{42}$. A diferença na distribuição, densidade e regulação da expressão $\mathrm{CB}_{1}$ entre sinapses inibitórias/excitatórias poderá ser a base molecular e anatômica para as ações perceptuais e motoras bifásicas da Cannabis (e derivados dela obtidos), as quais surgem de forma tempo e dose-dependente ${ }^{42}$.

Contudo, as preparações de Cannabis têm composição complexa e variável, incluindo outros canabinoides além do $\Delta^{9}$-THC, os quais podem complexificar as interferências neuroplásticas. Por exemplo, o $\Delta^{9}-\mathrm{THC}$ liga-se e ativa $\mathrm{CB}_{1}$ (e $\mathrm{CB}_{2}$ ), enquanto o canabidiol não se liga ao $C B_{1}$, mas inibe a recaptação e a metabolização dos endocanabinoides, aumentando a oferta sináptica para atuação nos $C_{1}$ e receptores vaniloides ${ }^{24,40}$. Por outro lado, ambos se ligam a canais tipo transient receptor potential (vanilloid type 2, TRPV2, e ankyrin-1, TRPA 1), os quais podem mediar alguns dos efeitos desses canabinoides $^{40}$. O resultado final dependerá do balanço dos efeitos de cada constituinte.

\section{CONCLUSÃO}

Dadas as áreas de intervenção e as interferências com a plasticidade, os endocanabinoides modulam a percepção emocional e sensorial, homeostase emocional e motivacional. O SEC exerce, portanto, um efeito modulatório global em vias cruciais na fenomenologia dos transtornos por uso de substâncias, postulando-se que contribua para a definição de setpoints em diversas vias neuronais; estes se tornarão mais permissivos no contexto do uso de substâncias psicotrópicas, nomeadamente Cannabis. Assim, a modulação do SEC poderá constituir no futuro um alvo terapêutico não só no tratamento dos transtornos por uso de Cannabis, mas também nos transtornos por uso de substâncias em geral, visando a uma postulada interrupção da progressão de consumo e/ou diminuição de recaídas; isso representaria enorme avanço perante o limitado panorama terapêutico vigente nos transtornos por uso de Cannabis (abuso e dependência).

\section{CONFLITO DE INTERESSE}

Os autores declaram não haver conflito de interesse.

\section{AGRADECIMENTOS}

À Universidade Federal de São Paulo/Escola Paulista de Medicina, na figura do professor doutor Benjamin Kopelman e da Profa Vera Salvadori, pelo empenho em encontrar um cocoordenador de relevância para este projeto.
Ao professor Elisaldo Araújo Carlini, por ter assumido a cocoordenação, pelo tempo comigo despendido, pelos incontáveis contributos intelectuais.

Ao Centro Brasileiro de Informações sobre Drogas Psicotrópicas, pelas instalações concedidas para as reuniões para a elaboração deste artigo.

À professora doutora Maria Amélia Ferreira, pelas incontornáveis ajudas aos obstáculos que foram surgindo durante a concretização deste projeto.

\section{REFERÊNCIAS}

1. Orta G. Coloquios dos simples e drogas da India. 1a ed. Lisboa: Academia Real das Sciencias de Lisboa/Imprensa Nacional; 1891.

2. Moreau (De Tours) J. Du Haschisch et de l'alienation mentale: etudes psychologiques. $1^{\text {st }}$ ed. Paris: Librairie de Fortin, Masson; 1845.

3. Zuardi AW. History of Cannabis as a medicine: a review. Rev Bras Psiquiatr. 2006;28(2):153-7.

4. Snyder SH. Uses of marijuana. $1^{\text {st }}$ ed. New York: Oxford University Press; 1971. p. 19-40.

5. Baudelaire C. Les paradis artificiels. 1 ${ }^{\text {st }}$ ed. Paris: Poulet-Malassis \& De Broise; 1860.

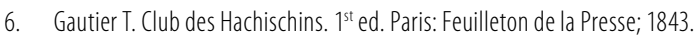

7. Hazekamp A. Medicinal use of Cannabis: a review. Leiden, The Netherlands: Leiden University, Department of Plant Metabolomics; 2008.

8. Carlini EA. A história da maconha no Brasil. J Bras Psiquiatr. 2006;55(4):314-7.

9. Fattore L, Fadda P, Spano MS, Pistis M, Fratta W. Neurobiological mechanisms of cannabinoid addiction. Mol Cell Endocrinol. 2008;286(1-2 Suppl 1):S97-107.

10. Cooper ZD, Haney M. Cannabis reinforcement and dependence: role of the cannabinoid CB1 receptor. Addict Biol. 2008;13(2):188-95.

11. McRae-Clark AL, Carter RE, Killeen TK, Carpenter MJ, Wahlquist AE, Simpson SA, et al. A placebo-controlled trial of buspirone for the treatment of marijuana dependence. Drug Alcohol Depend. 2009;105(1-2):132-8.

12. Elkashef A, Vocci F, Huestis M, Haney M, Budney A, Gruber A, et al. Marijuana neurobiology and treatment. Subst Abus. 2008;29(3):17-29.

13. Vandrey R, Haney M. Pharmacotherapy for Cannabis dependence: how close are we? CNS Drugs. 2009;23(7):543-53.

14. Dennis M, Babor TF, Roebuck MC, Donaldson J. Changing the focus: the case for recognizing and treating Cannabis use disorders. Addiction. 2002;97(Suppl 1):4-15.

15. Budney AJ, Lile JA. Moving beyond the Cannabis controversy into the world of the cannabinoids. Int Rev Psychiatry. 2009;21(2):91-5.

16. Hart CL. Increasing treatment options for Cannabis dependence: a review of potential pharmacotherapies. Drug Alcohol Depend. 2005;80(2):147-59.

17. OMS. Classificação de Transtornos Mentais e de Comportamento da Classificação Estatística Internacional de Doenças e Problemas Relacionados à Saúde (CID-10). 10a ed. Porto Alegre: Artes Médicas Sul Ltda.; 1993.

18. Cooper ZD, Haney M. Actions of delta-9-tetrahydrocannabinol in Cannabis: relation to use, abuse, dependence. Int Rev Psychiatry. 2009;21(2):104-12.

19. Ashton CH. Pharmacology and effects of Cannabis: a brief review. Br J Psychiatry. 2001;178:101-6.

20. Clapper JR, Mangieri RA, Piomelli D. The endocannabinoid system as a target for the treatment of Cannabis dependence. Neuropharmacology. 2009;56(Suppl 1):235-43.

21. El-Alfy AT, Ivey K, Robinson K, Ahmed S, Radwan M, Slade D, et al. Antidepressant-like effect of delta9-tetrahydrocannabinol and other cannabinoids isolated from Cannabis sativa L. Pharmacol Biochem Behav. 2010;95(4):434-42.

22. Mechoulam R, Hanus L. A historical overview of chemical research on cannabinoids. Chem Phys Lipids. 2000;108(1-2):1-13.

23. De Petrocellis $L$, Di Marzo V. An introduction to the endocannabinoid system: from the early to the latest concepts. Best Pract Res Clin Endocrinol Metab. 2009;23(1):1-15.

24. Mackie K. From active ingredients to the discovery of the targets: the cannabinoid receptors. Chem Biodivers. 2007;4(8):1693-706.

25. Elphick MR, Egertova M. The neurobiology and evolution of cannabinoid signalling. Philos Trans R Soc Lond B Biol Sci. 2001;356(1407):381-408. 
26. Wang J, Ueda N. Biology of endocannabinoid synthesis system. Prostaglandins Other Lipid Mediat. 2009;89(3-4):112-9.

27. Mackie K. Mechanisms of CB1 receptor signaling: endocannabinoid modulation of synaptic strength. Int J Obes (Lond). 2006;30(Suppl 1):S19-23.

28. Alger BE. Retrograde signaling in the regulation of synaptic transmission: focus on endocannabinoids. Prog Neurobiol. 2002;68(4):247-86.

29. Svizenska I, Dubovy P, Sulcova A. Cannabinoid receptors 1 and 2 (CB1 and (B2), their distribution, ligands and functional involvement in nervous system structures: a short review. Pharmacol Biochem Behav. 2008;90(4):501-11.

30. De Vries TJ, Schoffelmeer AN. Cannabinoid CB1 receptors control conditioned drug seeking. Trends Pharmacol Sci. 2005;26(8):420-6.

31. Laviolette SR, Grace AA. Cannabinoids Potentiate Emotional Learning Plasticity in Neurons of the Medial Prefrontal Cortex through Basolateral Amygdala Inputs. J Neurosci. 2006;26(24):6458-68.

32. Lutz B. The endocannabinoid system and extinction learning. Mol Neurobiol. 2007;36(1):92-101.

33. Misner DL, Sullivan JM. Mechanism of cannabinoid effects on long-term potentiation and depression in hippocampal CA1 neurons. J Neurosci. 1999;19(16):6795-805.

34. Ranganathan $M, D^{\prime}$ Souza $D C$. The acute effects of cannabinoids on memory in humans: a review. Psychopharmacology (Berl). 2006;188(4):425-44.

35. Robbe D, Alonso G, Manzoni 0J. Exogenous and endogenous cannabinoids control synaptic transmission in mice nucleus accumbens. Ann N Y Acad Sci. 2003;1003:212-25.

36. Azad SC, Monory K, Marsicano G, Cravatt BF, Lutz B, Zieglgansberger W, et al. Circuitry for associative plasticity in the amygdala involves endocannabinoid signaling. J Neurosci. 2004;24(44):9953-61.

37. Gerdeman GL, Partridge JG, Lupica CR, Lovinger DM. It could be habit forming: drugs of abuse and striatal synaptic plasticity. Trends Neurosci. 2003;26(4):184-92.

38. Chevaleyre V, Takahashi KA, Castillo PE. Endocannabinoid-mediated synaptic plasticity in the CNS. Annu Rev Neurosci. 2006;29:37-76.

39. Mackie K. Signaling via CNS cannabinoid receptors. Mol Cell Endocrinol. 2008;286(1-2 Suppl 1):S60-5.

40. Breivogel CS, Sim-Selley LJ. Basic neuroanatomy and neuropharmacology of cannabinoids. Int Rev Psychiatry. 2009;21(2):113-21.

41. Lovinger DM. Presynaptic modulation by endocannabinoids. Handb Exp Pharmacol. 2008(184):435-77.

42. Kano M, Ohno-Shosaku T, Hashimotodani Y, Uchigashima M, Watanabe M. Endocannabinoid-mediated control of synaptic transmission. Physiol Rev. 2009;89(1):309-80.

43. Pertwee RG. Pharmacological actions of cannabinoids. Handb Exp Pharmacol. 2005(168):1-51.

44. Oddi S, Spagnuolo P, Bari M, D’Agostino A, Maccarrone M. Differential modulation of type 1 and type 2 cannabinoid receptors along the neuroimmune axis. Int Rev Neurobiol. 2007;82:327-37.

45. Piomelli D. The endogenous cannabinoid system and the treatment of marijuana dependence. Neuropharmacology. 2004;47(Suppl 1):359-67.

46. Cajal SR. Significacion fisiologica de las expansiones protoplasmaticas y nerviosas de las celulas de la sustancia gris. Barcelona: Rev Cienc Méd. 1891.

47. Diana MA, Marty A. Endocannabinoid-mediated short-term synaptic plasticity: depolarization-induced suppression of inhibition (DSI) and depolarization-induced suppression of excitation (DSE). Br J Pharmacol. 2004;142(1):9-19.

48. Heifets BD, Castillo PE. Endocannabinoid signaling and long-term synaptic plasticity. Annu Rev Physiol. 2009;71:283-306.

49. Simon GM, Cravatt BF. Anandamide biosynthesis catalyzed by the phosphodiesterase GDE1 and detection of glycerophospho-N-acyl ethanolamine precursors in mouse brain. J Biol Chem. 2008;283(14):9341-9.

50. Slanina KA, Roberto M, Schweitzer P. Endocannabinoids restrict hippocampal long-term potentiation via (B1. Neuropharmacology. 2005;49(5):660-8.

51. Zhu PJ, Lovinger DM. Persistent synaptic activity produces long-lasting enhancement of endocannabinoid modulation and alters long-term synaptic plasticity. J Neurophysiol. 2007;97(6):4386-9.

52. Chiu CQ, Castillo PE. Input-specific plasticity at excitatory synapses mediated by endocannabinoids in the dentate gyrus. Neuropharmacology. 2008;54(1):68-78.

53. Diana MA, Bregestovski P. Calcium and endocannabinoids in the modulation of inhibitory synaptic transmission. Cell Calcium. 2005;37(5):497-505.

54. Fortin DA, Levine ES. Differential effects of endocannabinoids on glutamatergic and GABAergic inputs to layer 5 pyramidal neurons. Cereb Cortex. 2007;17(1):163-74.
55. Chevaleyre V, Heifets BD, Kaeser PS, Sudhof TC, Castillo PE. Endocannabinoid-mediated long-term plasticity requires CAMP/PKA signaling and RIM1alpha. Neuron. 2007;54(5):801-12

56. Marinelli S, Pacioni S, Bisogno T, Di Marzo V, Prince DA, Huquenard JR, et al. The endocannabinoid 2-arachidonoylglycerol is responsible for the slow self-inhibition in neocortical interneurons. J Neurosci. 2008;28(50):13532-41.

57. Wickens JR. Synaptic plasticity in the basal ganglia. Behav Brain Res. 2009;199(1):119-28.

58. Tzounopoulos T, Rubio ME, Keen JE, Trussell LO. Coactivation of pre- and postsynaptic signaling mechanisms determines cell-specific spike-timing-dependent plasticity. Neuron. 2007;54(2):291-301.

59. Safo PK, Regehr WG. Endocannabinoids control the induction of cerebellar LTD. Neuron. 2005;48(4):647-59.

60. Gerdeman GL, Lovinger DM. Emerging roles for endocannabinoids in long-term synaptic plasticity. Br J Pharmacol. 2003;140(5):781-9.

61. Chevaleyre V, Castillo PE. Heterosynaptic LTD of hippocampal GABAergic synapses: a novel role of endocannabinoids in regulating excitability. Neuron. 2003;38(3):461-72.

62. Chevaleyre V, Castillo PE. Endocannabinoid-mediated metaplasticity in the hippocampus. Neuron. 2004;43(6):871-81.

63. Rouach $N$, Nicoll RA. Endocannabinoids contribute to short-term but not long-term mGluR-induced depression in the hippocampus. Eur J Neurosci. 2003;18(4):1017-20.

64. Lafourcade CA. Presynaptic mechanisms of endocannabinoid-mediated long-term depression in the hippocampus. J Neurophysiol. 2009;102(4):2009-12.

65. Mato S, Lafourcade M, Robbe D, Bakiri Y, Manzoni 0J. Role of the cyclic-AMP/PKA cascade and of P/Q-type $\mathrm{Ca}++$ channels in endocannabinoid-mediated long-term depression in the nucleus accumbens. Neuropharmacology. 2008;54(1):87-94.

66. Maldonado R, Valverde 0 , Berrendero F. Involvement of the endocannabinoid system in drug addiction. Trends Neurosci. 2006;29(4):225-32.

67. Gardner EL. Endocannabinoid signaling system and brain reward: emphasis on dopamine. Pharmacol Biochem Behav. 2005;81(2):263-84.

68. Gardner EL. Addictive potential of cannabinoids: the underlying neurobiology. Chem Phys Lipids. 2002;121(1-2):267-90.

69. Fernandez-Ruiz J, Hernandez M, Ramos JA. Cannabinoid-dopamine interaction in the pathophysiology and treatment of CNS disorders. CNS Neurosci Ther. 2010;16(3):e72-91.

70. Lupica CR, Riegel AC, Hoffman AF. Marijuana and cannabinoid regulation of brain reward circuits. Br J Pharmacol. 2004;143(2):227-34.

71. Solinas M, Yasar S, Goldberg SR. Endocannabinoid system involvement in brain reward processes related to drug abuse. Pharmacol Res. 2007;56(5):393-405.

72. Yamamoto T, Anggadiredja K, Hiranita T. New perspectives in the studies on endocannabinoid and Cannabis: a role for the endocannabinoid-arachidonic acid pathway in drug reward and long-lasting relapse to drug taking. J Pharmacol Sci. 2004;96(4):382-8.

73. Lichtman AH, Varvel SA, Martin BR. Endocannabinoids in cognition and dependence. Prostaglandins Leukot Essent Fatty Acids. 2002;66(2-3):269-85.

74. Chiu CQ, Puente N, Grandes P, Castillo PE. Dopaminergic modulation of endocannabinoid-mediated plasticity at GABAergic synapses in the prefrontal cortex. J Neurosci. 2010;30(21):7236-48.

75. Lopez-Moreno JA, Gonzalez-Cuevas G, Moreno G, Navarro M. The pharmacology of the endocannabinoid system: functional and structural interactions with other neurotransmitter systems and their repercussions in behavioral addiction. Addict Biol. 2008;13(2):160-87.

76. Hoffman AF, Oz M, Yang R, Lichtman AH, Lupica CR. Opposing actions of chronic Delta9-tetrahydrocannabinol and cannabinoid antagonists on hippocampal long-term potentiation. Learn Mem. 2007;14(1-2):63-74.

77. Hoffman AF, $0 z$ M, Caulder T, Lupica CR. Functional tolerance and blockade of long-term depression at synapses in the nucleus accumbens after chronic cannabinoid exposure. J Neurosci. 2003;23(12):4815-20.

78. Fan N, Yang H, Zhang J, Chen C. Reduced expression of glutamate receptors and phosphorylation of CREB are responsible for in vivo Delta9-THC exposure-impaired hippocampal synaptic plasticity. J Neurochem. 2010;112(3):691-702.

79. Gonzalez S, Cebeira M, Fernandez-Ruiz J. Cannabinoid tolerance and dependence: a review of studies in laboratory animals. Pharmacol Biochem Behav. 2005;81(2):300-18.

80. Fattore L, Spano MS, Deiana S, Melis V, Cossu G, Fadda P, et al. An endocannabinoid mechanism in relapse to drug seeking: a review of animal studies and clinical perspectives. Brain Res Rev. 2007;53(1):1-16. 